\author{
Military Technical College \\ Kobry El-Kobbah, \\ Cairo, Egypt.
}

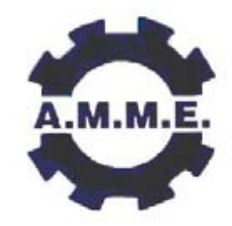

\author{
$13^{\text {th }}$ International Conference \\ on Applied Mechanics and \\ Mechanical Engineering.
}

\title{
NUMERICAL INVESTIGATION OF FATIGUE LIFE ON OPTIMUM AUTOFRETTAGED PRESSURIZED THICK-WALLED CYLINDERS
}

\author{
BIN AYOB ${ }^{*}$ A. and ELBASHEER ${ }^{* *}$ M.K.
}

\begin{abstract}
The numerical study presents a procedure to determine the optimum autofrettage pressure for a given operating pressure, so as to achieve the longest fatigue service life of thick-walled cylinders. The study investigates the fatigue life of pressurized cylinders under the effect of applied cyclic internal operating pressure. The cylinders had previously undergone a process of optimum autofrettage to induce a minimum total equivalent stress under the operating pressure. A nonlinear material property with a kinematic hardening was used. Experiments were carried out to validate the numerical results of residual stress where strain gages provided the strain values used to find the hoop stresses present on the outer surface. There was good agreement between the FE simulation and the strain measurement in obtaining residual stresses. The performance of the cylinders was evaluated in terms of fatigue damage accumulation for various levels of autofrettage. The results clearly indicate the importance of autofrettage in increasing the fatigue life. In increasing the autofrettage level, the fatigue life increases first, reaches a maximum optimum level and then decreases. In conclusion, optimum autofrettage level leads to an optimum fatigue life.
\end{abstract}

\section{KEY WORDS}

Finite Element, Optimum Autofrettage, Residual Stress, Optimum Fatigue Life Prediction.

\footnotetext{
* Associate professor. Faculty of Mech. Engineering, Universiti Teknologi Malaysia

** Postgraduate student, Faculty of Mech. Engineering, Universiti Teknologi Malaysia
} 


\section{NOMENCLATURE}

$\begin{array}{ll}\mathrm{E} & \text { elastic modulus } \\ \mathrm{k} & \text { Outer : inner radius ratio } \\ \mathrm{m} & \text { Autofrettage :inner radius ratio } \\ \mathrm{n} & \text { operating pressure: yield stress ratio } \\ \text { opr } & \text { operating } \\ \text { opt } & \text { optimum } \\ \mathrm{P} & \text { pressure } \\ \mathrm{r} & \text { radius } \\ \mathrm{r}_{\mathrm{a}} & \text { autofrettage radius } \\ \mathrm{Y} & \text { yield } \\ \mathrm{Z} & \text { axial } \\ \theta & \text { hoop } \\ \sigma & \text { normal stress } \\ \mathrm{v} & \text { Poisson's ratio }\end{array}$

\section{INTRODUCTION}

The ever-increasing industrial demand for axisymmetrical thick-walled cylinders has found applications in chemical, nuclear reactors, fluid transmitting plant, power generation plant and military equipment with very critical regulation of design and safe service. Therefore, in order to ensure safety from unexpected fatigue failure and to extend the lifetime of the thick-walled cylinders, fatigue life analysis has been of great importance. The progressive scarcity and higher cost of materials have led researchers and designers not to confine themselves to the customary elastic region and diverted their attention to the elastic-plastic approach that offers a more efficient use of materials.

To increase the maximum allowable pressure in the vessel as well as to reduce susceptibility to cracking, desired residual stresses are introduced to the cylinder wall, usually by autofrettage process. When a thick-walled cylinder is subjected to cyclic internal operating pressure, fatigue cracks generally form and propagate at the inner surface where maximum tensile hoop stress occurs [1]. Autofrettage is a plastic deformation process caused by imposing a very high internal pressure, resulting in compressive and tensile hoop residual stresses at the inside and outside surfaces of the cylinder, respectively. This results in increased load carrying capacity, gross resistance to fatigue and inhibit the rate of crack propagation [2]. The autofrettage process introduces favourable residual compressive stresses in the region of expected high tensile stresses. This process allows a higher service pressure in the vessel and decreases cylinder susceptibility to inner cracking [3, 4]. Many studies have investigated plain thick-walled cylinders based on the minimization of maximum stress to improve the cylinder lifetime. In this study, an autofrettage process technique is developed to obtain stress redistribution which can result in an optimum fatigue life.

Experiments by Rees [5] showed that fatigue failures under repeated pressure in rifledbored cylinders are caused by the simultaneous propagation of many cracks. In contrast to this, plain-bored cylinders fail from the propagation of a single elliptical, longitudinal crack. Clark [6] carried out experiments to determine the effects of various 
residual stress distributions on the growth rate of fatigue cracks. The experiments provided direct evidence that the effects of residual stress on the crack tip stress intensity may be modeled conveniently using weight function techniques, and can be incorporated satisfactorily in fatigue crack growth analyses. In Tomkins's [7] analysis, the fatigue failure of plain thick-walled cylinders under repeated internal pressure were considered with a view to establishing a general criteria for failure which can be of use in design. It was found that the fatigue behavior of cylinders could be adequately predicted from conventional material fatigue data when the complexities of the elasticplastic stress-strain state in a pressurized cylinder are taken into account.

\section{CYLINDER SUBJECTED TO INTERNAL PRESSURE}

Consider a thick-walled cylinder with inner radius $r_{i}$ and outer radius $r_{0}$ which is subjected to an internal pressure, $\mathrm{P}_{\mathrm{i}}$. The radial stress, $\sigma_{\mathrm{r}}$, and circumferential stress, $\sigma_{\theta}$, distributions are given by Lame's formulation [8, 9]:

$$
\begin{aligned}
& \sigma_{r}=\frac{P_{i}}{k^{2}-1}\left[1-\frac{r_{o}^{2}}{r^{2}}\right] \\
& \sigma_{\theta}=\frac{P_{i}}{k^{2}-1}\left[1+\frac{r_{o}^{2}}{r^{2}}\right]
\end{aligned}
$$

For a cylinder with end caps and free to change in length, the axial stress is given by:

$$
\sigma_{z}=\frac{P_{i}}{k^{2}-1}
$$

where the non-dimensional parameter, $k=\frac{r_{0}}{r_{i}}$

The internal pressure to cause yielding to a depth of $r$ is given by $[10,11]$ :

$$
P=\frac{\sigma_{Y}}{2}\left[\left(1-\frac{r^{2}}{r_{o}^{2}}+2 \ln \frac{r}{r_{i}}\right]\right.
$$

Using Tresca and von Mises yield criteria respectively [12, 13], yielding occurs when:

$$
\begin{aligned}
& \left(\sigma_{\theta}-\sigma_{r}\right)=\sigma_{Y} \\
& \sqrt{\frac{1}{2}\left\{\left(\sigma_{\theta}-\sigma_{r}\right)^{2}+\left(\sigma_{r}-\sigma_{z}\right)^{2}+\left(\sigma_{z}-\sigma_{\theta}\right)^{2}\right\}}=\sigma_{Y}
\end{aligned}
$$

\section{RESIDUAL STRESSES}

In autofrettage when the pressure is released the residual stresses lead to a decrease in the maximum equivalent stress during the working loading stage. Favorable 
compressive and tensile residual stresses are introduced to the inner and outer surfaces of the cylinder wall respectively. Assuming that during unloading the material follows Hooke's Law; the residual stresses at junction radius $r_{a}$ are obtained [14]:

$$
\begin{aligned}
& \sigma_{r, R}=\frac{\sigma_{Y}}{2}\left[1-\frac{k^{2}}{m^{2}}\right]\left\{\frac{m^{2}}{k^{2}}-\left[1-\frac{m^{2}}{k^{2}}+2 \ln m\right]\left[\frac{1}{k^{2}-1}\right]\right\} \\
& \sigma_{\theta, R}=\frac{\sigma_{Y}}{2}\left[1+\frac{k^{2}}{m^{2}}\right]\left\{\frac{m^{2}}{k^{2}}-\left[1-\frac{m^{2}}{k^{2}}+2 \ln m\right]\left[\frac{1}{k^{2}-1}\right]\right\} \\
& \sigma_{z, R}=\frac{\sigma_{Y}}{2}\left\{\frac{m^{2}}{k^{2}}-\left[1-\frac{m^{2}}{k^{2}}+2 \ln m\right]\left[\frac{1}{k^{2}-1}\right]\right\}
\end{aligned}
$$

where the non-dimensional parameter, $m=\frac{r_{a}}{r_{i}}$

The residual stress distributions in the cylinder thickness are shown in Fig.1. On application of the operating pressure the total stress of the autofrettaged cylinder is the summation of the residual stress and the stress due to the operating pressure:

$$
\begin{aligned}
& \sigma_{r, T}=\sigma_{r}+\sigma_{r, R} \\
& \sigma_{\theta, T}=\sigma_{\theta}+\sigma_{\theta, R} \\
& \sigma_{z, T}=\sigma_{z}+\sigma_{z, R}
\end{aligned}
$$

The stress distributions in the wall of the cylinder subjected to an operating pressure, after autofrettage are shown in Fig.2.

\section{THEORETICAL OPTIMUM AUTOFRETTAGE PRESSURE}

Autofrettage results in an increase in the pressure capacity of the cylinder. A key problem is to determine the optimum autofrettage pressure and the corresponding radius of the elastic-plastic boundary where the maximum equivalent stress in the cylinder becomes a minimum. Using Tresca yield theory, the equivalent stress at the elastic-plastic junction radius, $r_{a}$, is obtained, when the cylinder is subjected to internal operating pressure, after being treated with autofrettage:

$$
\sigma_{T r}=\sigma_{Y} \frac{k^{2}}{m^{2}}\left[\frac{m^{2}}{k^{2}}-\left(1-\frac{m^{2}}{k^{2}}+2 \ln m\right) \frac{1}{k^{2}-1}\right]+\left[\frac{2 P_{o p r}}{k^{2}-1}\right]\left(\frac{k^{2}}{m^{2}}\right)
$$

Differentiating Eqn. (9) and equating the differential to zero, $\frac{d \sigma_{T r}}{d m}=0$

to obtain $\quad m=\exp \left(\frac{P_{o p r}}{\sigma_{Y}}\right)$ 
The radius $r_{a}$ obtained is the optimum autofrettage radius $\left(r_{a}\right.$, opt $)$ and $\sigma_{T r}$ has a minimum value when $r_{a}=r_{a}$, opt. Autofrettage causes material plasticity to occur up to the elasticplastic junction line with radius $r_{a}$.

Using the non-dimensional parameter, $n=\frac{P_{o p r}}{\sigma_{Y}}$

therefore, $\quad r_{a, o p t, T r}=r_{i} e^{n} \quad m_{o p t, T r}=\exp (n)$

and

$$
r_{a, o p t, v M}=r_{i} e^{\frac{\sqrt{3}}{2} n} \quad m_{o p t, v M}=\exp \frac{\sqrt{3}}{2} n
$$

Therefore the optimum autofrettage pressure is:

$$
\begin{aligned}
& P_{a, o p t, T r}=\frac{\sigma_{Y}}{2}\left[1-\frac{e^{2 n}}{k^{2}}+2 n\right] \\
& P_{a, o p t, v M}=\frac{\sigma_{Y}}{2}\left[1-\frac{e^{\sqrt{3} n}}{k^{2}}+\sqrt{3} n\right]
\end{aligned}
$$

Fig. 3 shows the maximum total equivalent von Mises stress which occurs at the elasticplastic junction radius in the cylinder wall, for various levels of autofrettage, for a given operating pressure. The results indicate the existence of a minimum value of the maximum equivalent stress, which occurs at a specific value of autofrettage pressure.

\section{FATIGUE LIFE}

Fatigue life analysis is concerned with estimating the number of cycles to crack initiation and the number of cycles for crack propagation from initial to critical crack size. Compressive residual stresses are beneficial since they can improve the fatigue lives of machine components by reducing the cyclic stress. The maintainability of such residual stresses is dependent on material, magnitude of autofrettage pressure and cylinder geometry. The log-log linear relationship between stress amplitude and fatigue life is:

$$
\log _{10} \frac{\Delta \sigma}{2}=b \log _{10}\left(2 N_{f}\right)+\log _{10}\left(\sigma_{f}\right)
$$

and $\frac{\Delta \sigma}{2}=\sigma_{f}^{\prime}\left(2 N_{f}\right)^{b}$

i.e. a linear relationship which was proposed as early as 1910 [15]. The fatigue properties are listed in Table 1 . The fatigue life for the mathematically modeled strainlife method is the one most widely used. It is:

$$
\frac{\Delta \varepsilon}{2}=\frac{\sigma_{f}^{\prime}}{E}\left(2 N_{f}\right)^{b}+\varepsilon_{f}^{\prime}\left(2 N_{f}\right)^{c}
$$


For high cycle fatigue the equation reduces to,

$$
\frac{\Delta \varepsilon_{1}}{2}=\frac{\sigma_{f}^{\prime}}{E}\left(2 N_{f}\right)^{b}
$$

or in terms of true stress,

$$
\frac{\Delta \sigma_{1}}{2}=\frac{\sigma_{f}^{\prime}}{E}\left(2 N_{f}\right)^{b}
$$

\section{FINITE ELEMENT METHOD}

In this work, a numerical simulation is carried out, using Finite Element code ABAQUS v6.5.1 to analyze the nonlinear structure under cyclic internal operating pressure [16, 17]. A finite element model of a cylinder with an inside radius of $100 \mathrm{~mm}$ and outside radius of $200 \mathrm{~mm}$ was generated. Two-dimensional axisymmetric element was used with material SAE-950C Manten steel $(0.15 \% \mathrm{C})$, with the properties shown in Table 1. The FE model consisted of 5896 elements and 11456 nodes, and is shown in Fig. 4. The mesh was made adequately fine in order to produce a satisfactory result and at the same time avoiding considerable computing time. An autofrettage pressure of $202 \mathrm{MPa}$ was applied. The pressure was then released and the resulting residual stress distributions were evaluated in the thick-walled cylinder. From previous analysis, the cylinder had undergone a process of optimum autofrettage to induce a minimum total equivalent von Mises stress under the operating pressure of $130 \mathrm{MPa}$, as shown in Figs.3 and 5. Using FE-SAFE v5.0, the cylinder was reloaded with a cyclic internal operating pressure of $0-130 \mathrm{MPa}$. The objective was to study the effect of residual stresses, which had been created by the optimum autofrettage procedure, on the fatigue life of the cylinder. An elastic-plastic FE analysis was carried out using an appropriate kinematic hardening model usually used for fatigue analysis.

\section{EXPERIMENTAL PROCEDURES}

The purpose of the experiment was to verify the calculated stresses and to study the feasibility of using the strain gage technique to measure residual stresses on the outer surface of the cylinder. A tube specimen made of mild steel was chosen. The specimen had an outer diameter of $41 \mathrm{~mm}$ and a wall thickness of $4.5 \mathrm{~mm}$. From a tensile test performed on the tube material, the material has a Young's modulus of $210 \mathrm{GPa}$ and a Poisson's ratio of 0.3. The yield stress of the material is $306 \mathrm{MPa}$. Fig.6 shows the experimental test setup for the experiment. The internal pressure was applied through a manual hydraulic pump with pressure measured by a pressure transducer. Using strain gages, the hoop and axial strains on the outer surface were measured when the internal pressure was increased from zero to $P_{a}$, and subsequently when the autofrettage pressure was removed. The strains were monitored to control the pressure so as to avoid yield on the outer surface. Figs. 7 and 8 show a comparison between the axial and hoop strains during pressurization, and Fig. 9 shows a comparison of residual strains on the outer surface of cylinder obtained through experiment and numerical modeling. The average difference of the finite element results with respect to experimental results is about $14 \mu \varepsilon$, which is a practically acceptable value. The 
experiment demonstrates that the strain gage is a technique applicable to residual stress measurements in the outer surface of thick-walled cylinders.

\section{RESULTS AND DISCUSSION}

In this study, the finite element method is used for stress-strain analysis of pressurized thick-walled cylinder which was subjected to an internal operating pressure. An analytical solution is also presented in order to validate the simulation results. From FEM, comparing between Tresca and von Mises criteria, for an operating pressure of $130 \mathrm{MPa}$, the optimum autofrettage procedure gives results shown in Table 2. When this pressure is removed, the largest residual stresses are the hoop stresses at the inner surface of the cylinder, which are beneficial under subsequent internal pressure loading. The residual stresses lead to a decrease in the maximum equivalent stress in the working pressure stage, as shown in Fig.10, where autofrettage considerably reduces equivalent stress level in the inner surface and increasing it in the outer surface. In addition, autofrettage moves the location of high stress away from the critical inner surface where cracks usually initiate.

Figure 11 shows that with optimum autofrettage the magnitude of an internal pressure which is required to yield the tube at the inner surface is larger than in a nonautofrettaged tube. The effect of an increase in the internal pressure is significant for tubes with radius ratio $\mathrm{k}$ in the range of 1.2 to 4.7 . The higher the operating pressure, the lower is the internal pressure which causes yielding at the inner surface.

As shown in Fig.12, the benefit of a small level of autofrettage was an increase in the fatigue life of plain cylinders under cyclic internal operating pressure. As the level of autofrettage in increased, the fatigue life increases but up to a point where, with further increase in autofrettage level the fatigue life begin to decrease. In other words, there is an optimum level of autofrettage which corresponds to a maximum fatigue life of the cylinder, and this optimum level of autofrettage is the optimum autofrettage pressure for a given value of operating pressure. The autofrettage procedure increases the allowable internal operating pressure and elastic strength of a thick-walled cylinder, as shown in Figs.11 and 13 and in Table 3. In addition, as shown in Fig.14, to increase the absolute internal operating pressure or to increase the elastic strength area of pressurized thick-walled cylinder, treating with full autofrettage is much better than optimum autofrettage and subsequently better than non-treatment.

\section{CONCLUSIONS}

A theoretical study of stress analysis was carried out on thick-walled cylindrical pressure vessels subjected to cyclic internal operating pressure. A mathematical model has been developed to determine the optimum autofrettage pressure where the maximum equivalent von Mises stress in the cylinder becomes a minimum. The cylinder was then solved numerically for an optimum autofrettage level which will result in the most extended fatigue life. The optimum autofrettage pressure varies with the operating pressure that is used in the cylinder. Experimental work was carried out to validate the residual strain in the outer surface of cylinder. Autofrettage results in an increase the maximum allowable operating pressure, optimum autofrettage pressure reduce the maximum equivalent stress which was moved from inner surface to elastic- 
plastic junction line deeply in cylinder thickness. The fatigue life of optimum autofrettaged cylinders is found to be about 3.24 times greater than non-autofrettaged cylinders. As the autofrettage pressure level is increased the predicted fatigue life increased but only up to the optimum autofrettage pressure, after which the fatigue life will decrease with further increase of the autofrettage pressure level. The optimum autofrettage pressure leads to optimum fatigue life.

\section{REFERENCES}

[1] Shlyannikov, V.N. "Fatigue Shape Analysis for Internal Surface Flaw in a Pressurized Hollow Cylinder". International Journal of Pressure Vessels and Piping, Vol.77, pp 227-234, (2000).

[2] Perry, J. and Aboudi, J. "Elasto-plastic Stresses in Thick walled Cylinders". ASME Journal of Pressure Vessel Technology, Vol. 125, pp. 248-252, (2003).

[3] Thumser, R.J., Bergmann, J.W. and Vormwald, M. "Residual Stress Fields and Fatigue Analysis of Autofrettaged Parts". International Journal of Pressure Vessels and Piping, Vol.79, No.2, pp 113-117, (2002).

[4] Zhao, W., Seshadri, R. and Dubey, R.N. "On Thick-walled Cylinder under Internal Pressure”. ASME J. Press. Ves. Tech., Vol.25, pp 267-273, (2003).

[5] Rees, D.W.A. "Fatigue Crack Growth in Thick-walled Cylinders under Pulsating Internal Pressure". Engineering Fracture Mechanics, Vol.33, Issue 6, pp 927940, (1989).

[6] Clark, G. "Fatigue Crack Growth through Residual Stress Fields - Theoretical and Experimental Studies on Thick-walled Cylinders". Journal of Theoretical and Applied Fracture Mechanics, Vol.2, Issue 2, pp 111-125, (1984).

[7] Tomkins, B. "Fatigue Failure Criteria for Thick-walled Cylindrical Pressure Vessels". International Journal of Pressure Vessels and Piping, Vol.61, Issue 1, pp 37-59, (2002).

[8] Mott, "Applied Strength of Materials". Prentice Hall, New Jersey, Ohio, (2002)

[9] Shigley, J.E. and Mischke, C. R. "Mechanical Engineering Design", McGraw-Hill, Michigan, USA, (2004).

[10] Amer Hameed, Brown, R.D. and Hetherington, J. "A Study of the Residual Stress Distribution in an Autofrettaged Thick-walled Cylinder with Cross-bore". ASME Journal of Pressure Vessel Technology, Vol.126, pp 497-503, (2005).

[11] Chee, E. K. "Finite Element Modeling and Analysis of Residual Stresses in 2D Machining". PhD Thesis, University of Kentucky, (2002).

[12] Alexander, J.M. "Strength of Materials", New York, John Wiley, (1981).

[13] Cristescu, N.D., Eduard, M. C. and Eugen, S., "Mechanics of Elastic Composites". Chapman \& Hall, United Kingdom, (2004).

[14] Ayob, A..and Kabashi, M. "Influence of Optimum Autofrettage on Fatigue Life of Pressurized Thick-walled Cylinders". World Engineering Congress, Penang, Malaysia, pp 17 -26, (2007).

[15] Basquin, O.H. "The Exponential Law of Endurance Tests", American Society for Testing and Materials Proceedings, Vol.10, (1910).

[16] ABAQUS v6.5.1, "Standard User's Manual", New Jersey, Ohio, (2005).

[17] Majzoobia, G.H. and Farrahib, G.H. "Experimental and Finite Element Prediction of Bursting Pressure in Cylinders". International Journal of Pressure Vessels and Piping, Vol.81, pp 889-896, (2004). 
FIGURES AND TABLES

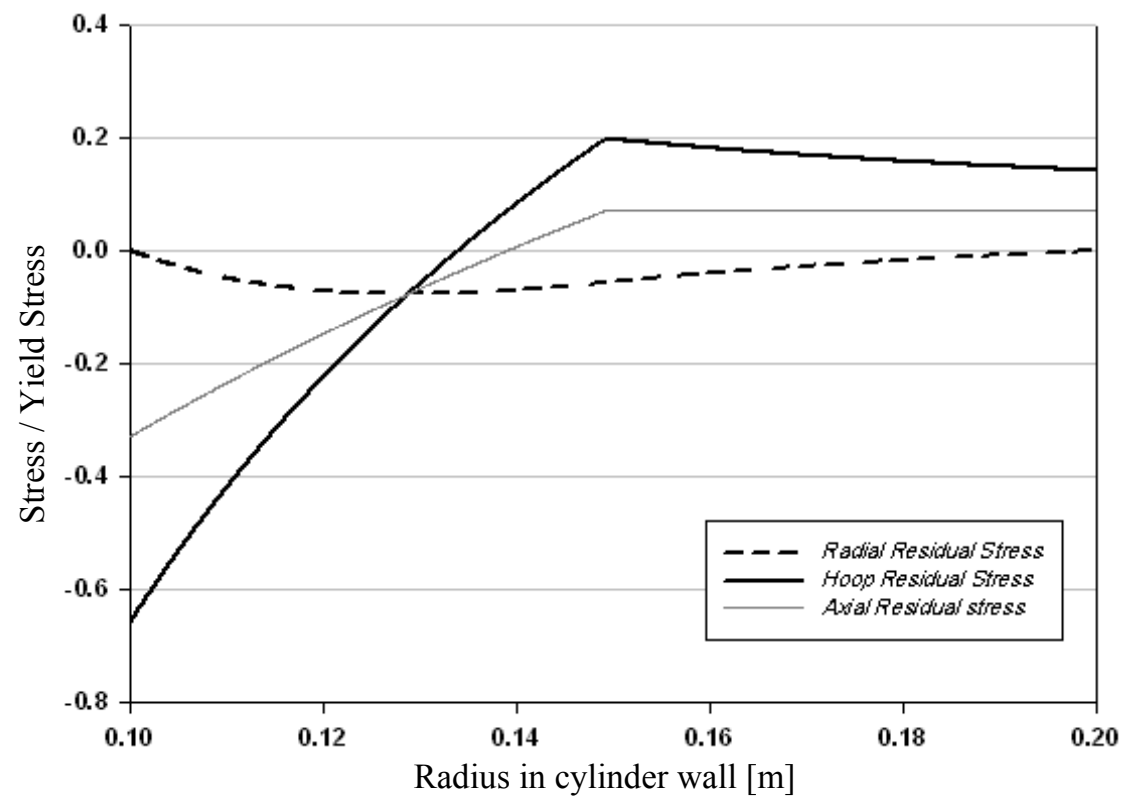

Fig.1. Residual stress distributions in cylinder wall, after autofrettage

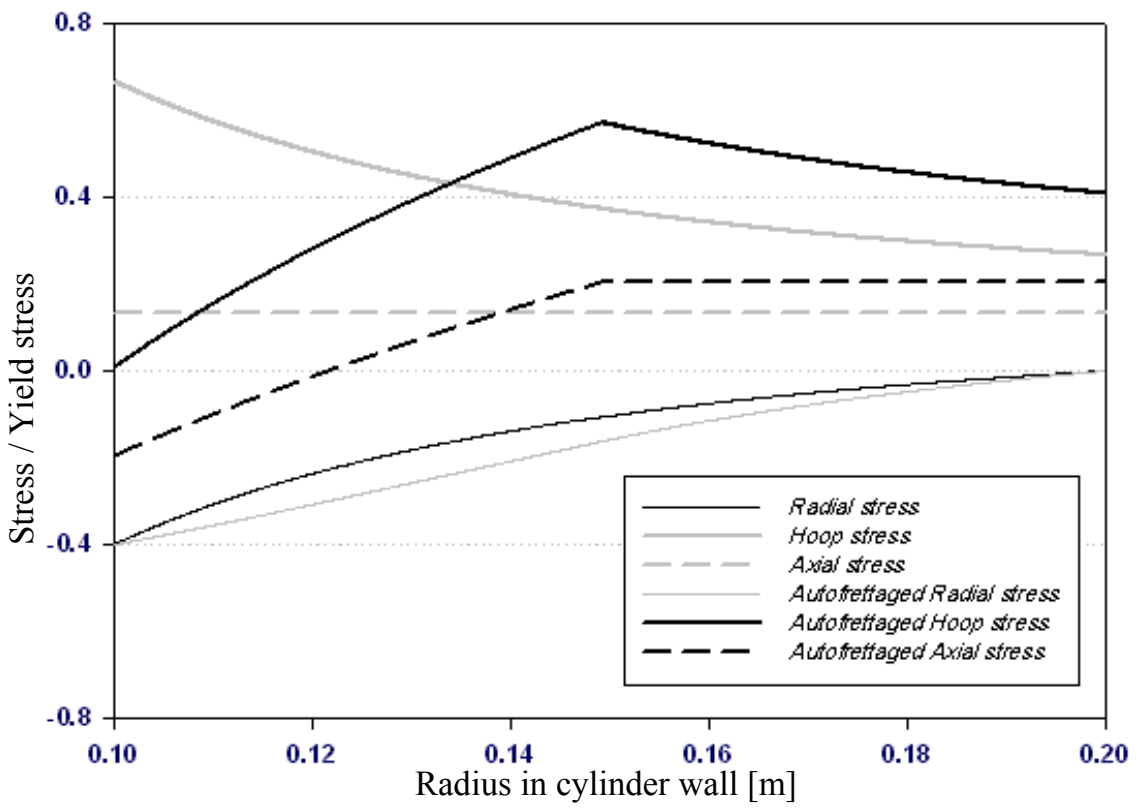

Fig.2. Total stress distributions in cylinder wall - autofrettaged and non-autofrettaged cylinder subjected to operating pressure 


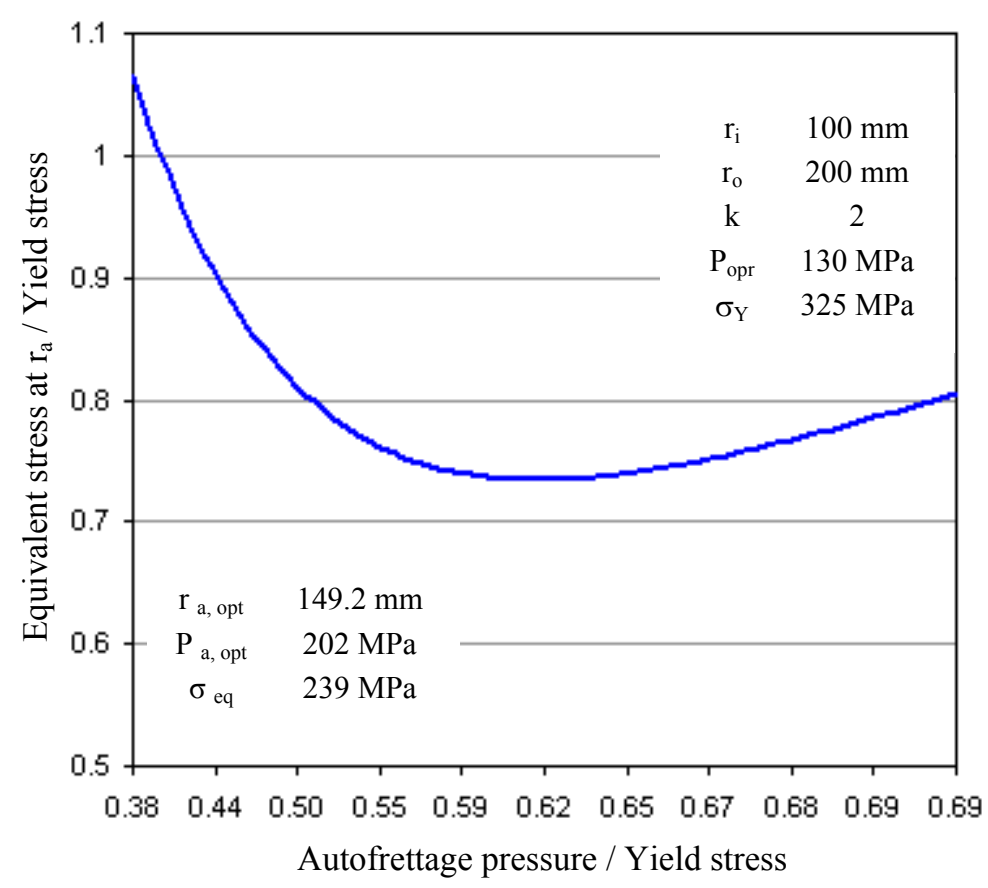

Fig.3. Occurrence of optimum autofrettage pressure
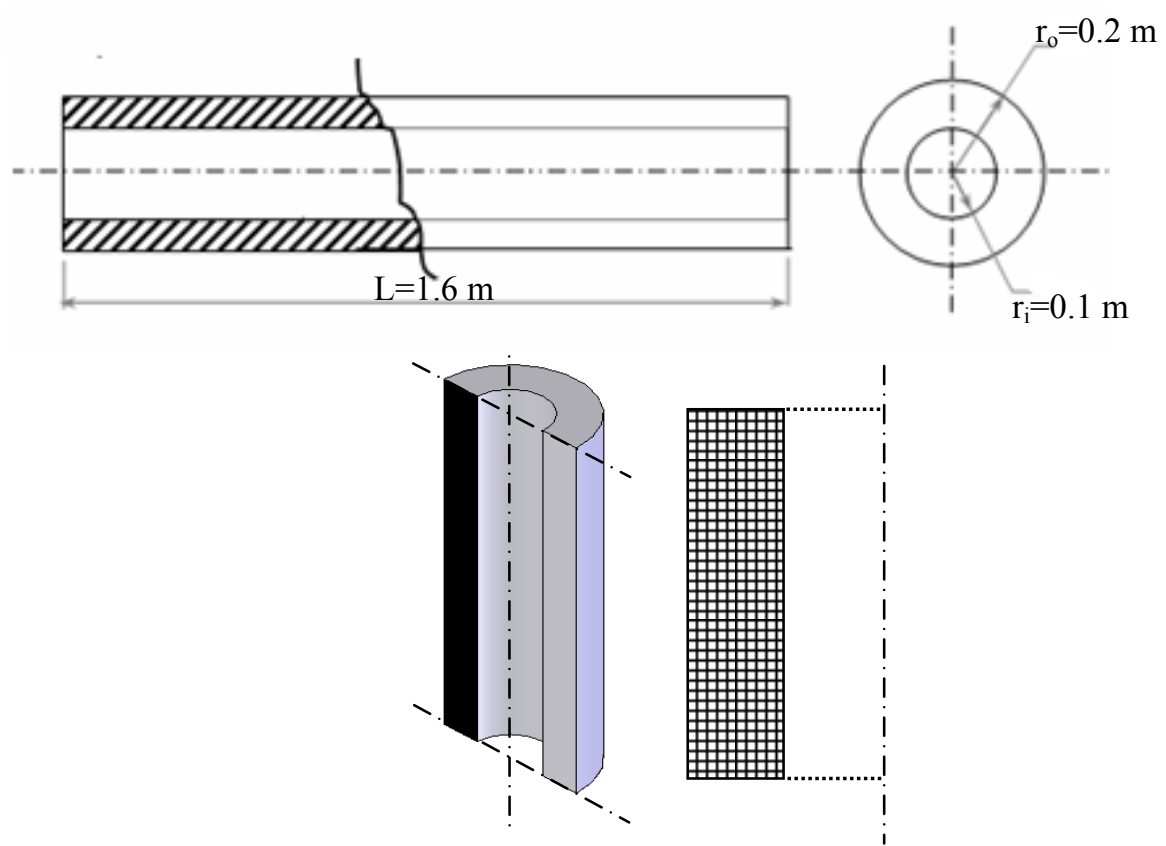

Fig. 4. Dimensions and axisymmetric model of plain thick-walled cylinder 

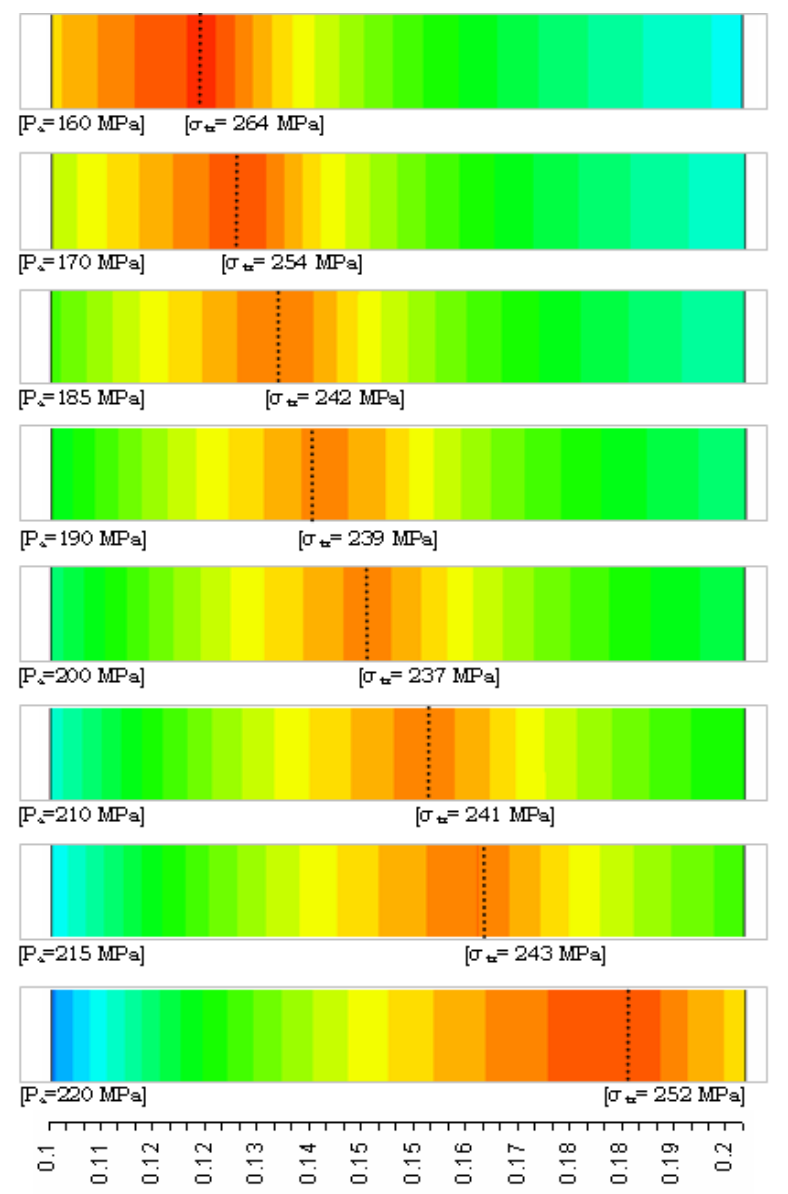

Fig.5. Effect of different levels of autofrettage on total von Mises stress distribution during operating stage

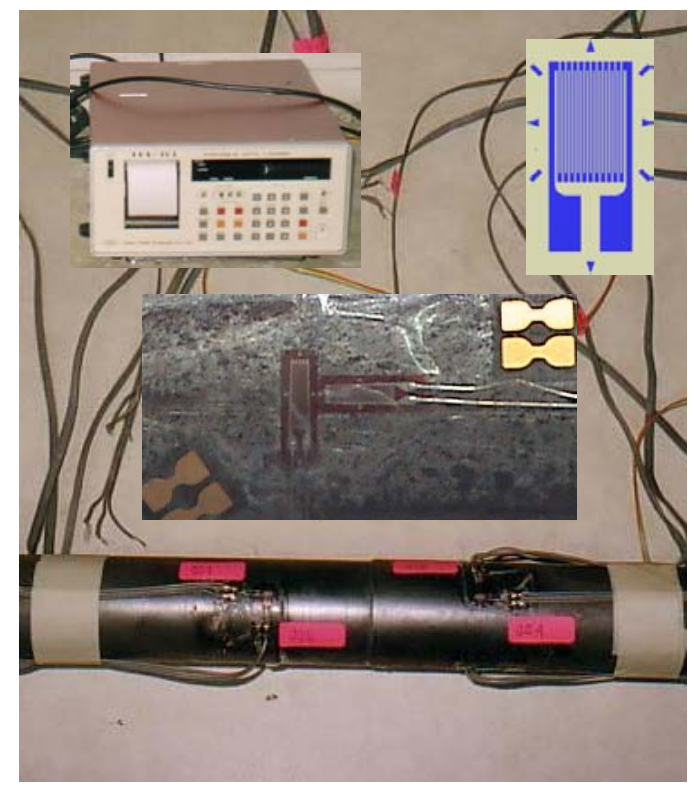

Fig.6. Specimen and equipment for experimental test 


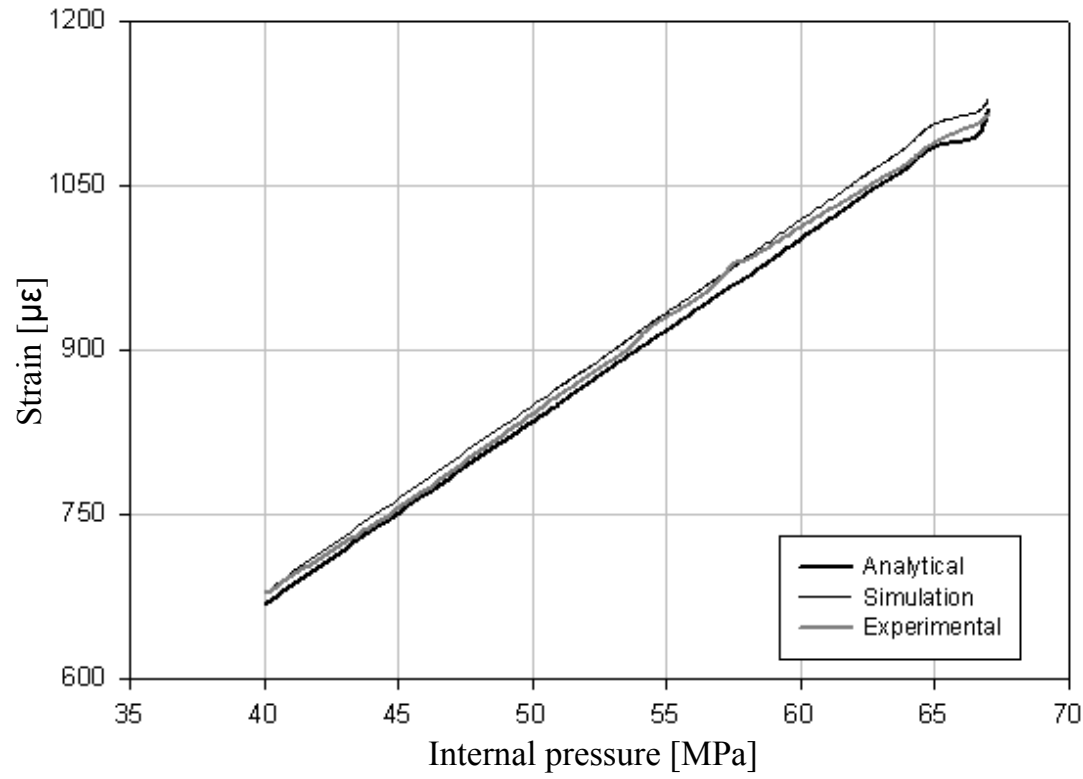

Fig.7. Comparison between analytical, experimental and numerical hoop strains

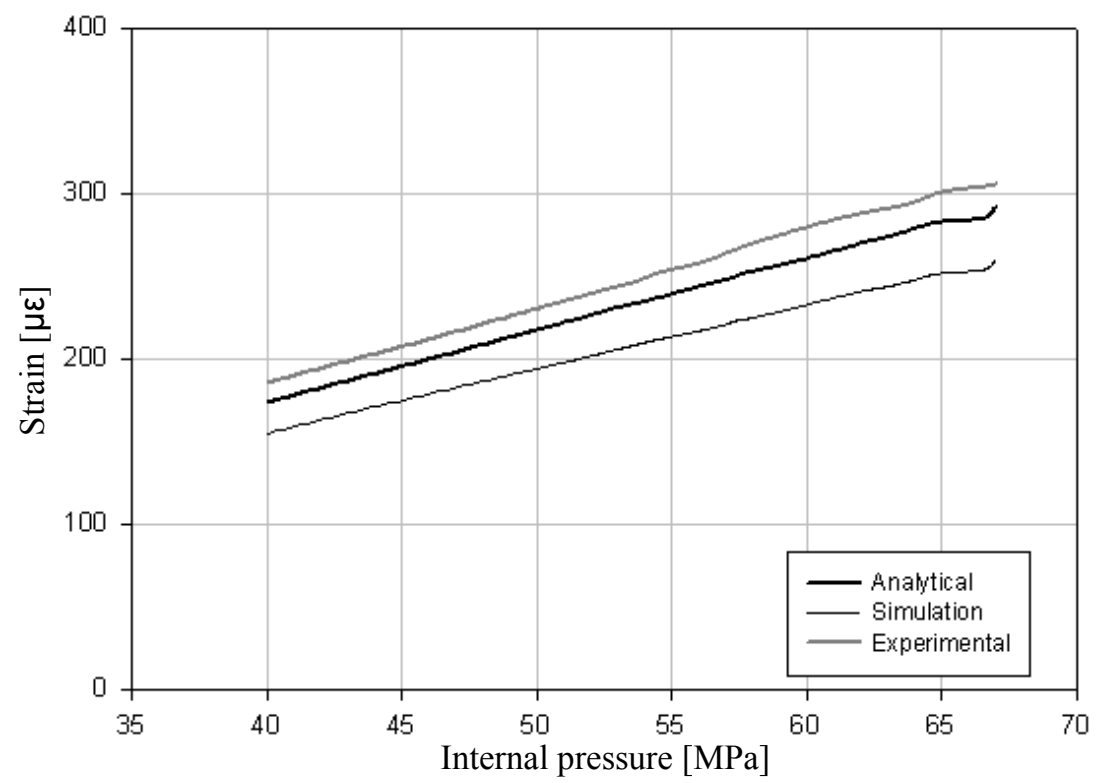

Fig.8. Comparison between analytical, experimental and numerical axial strains 


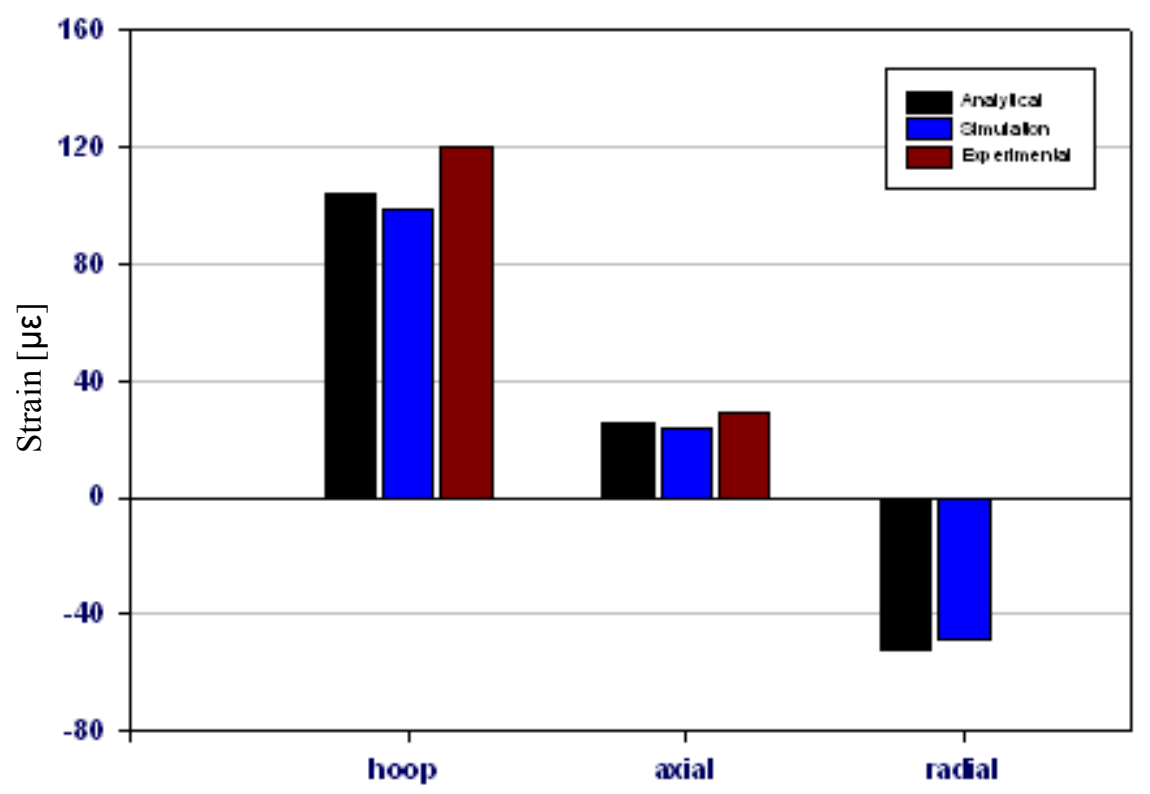

Fig. 9. Comparison between analytical, experimental and numerical residual strains at the outer surface of plain cylinder.

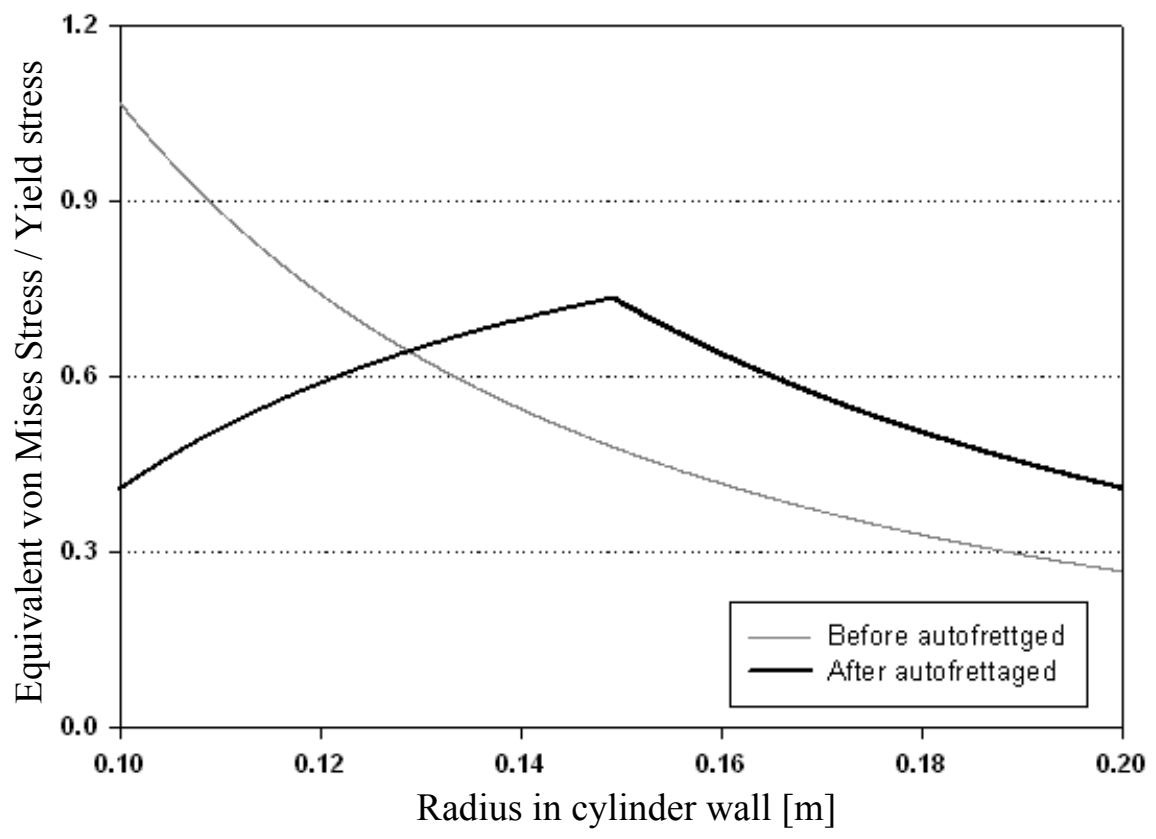

Fig.10. Total equivalent von Mises stress, before and after autofrettage 


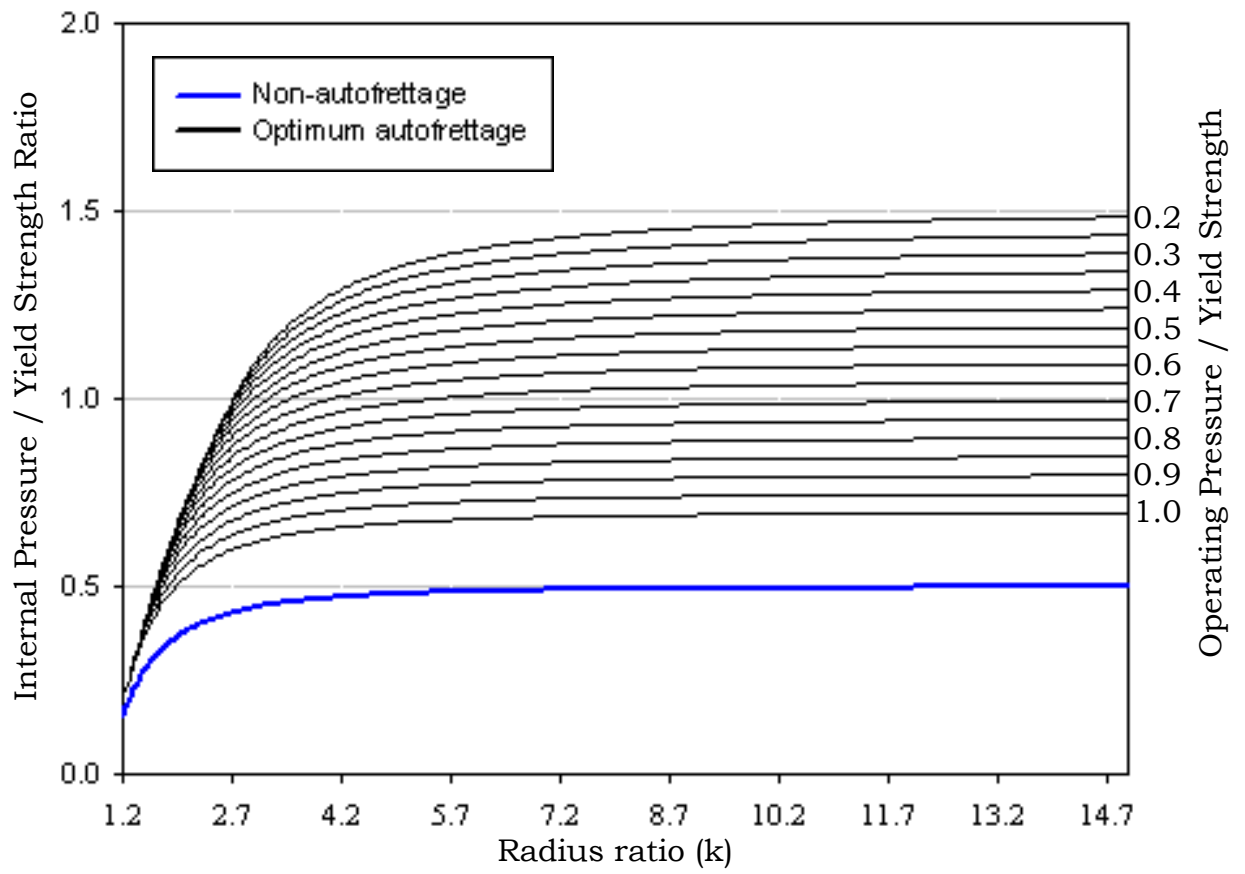

Fig.11. Internal pressure to cause inner surface to yield, with different optimum autofrettage levels - Tresca criterion 

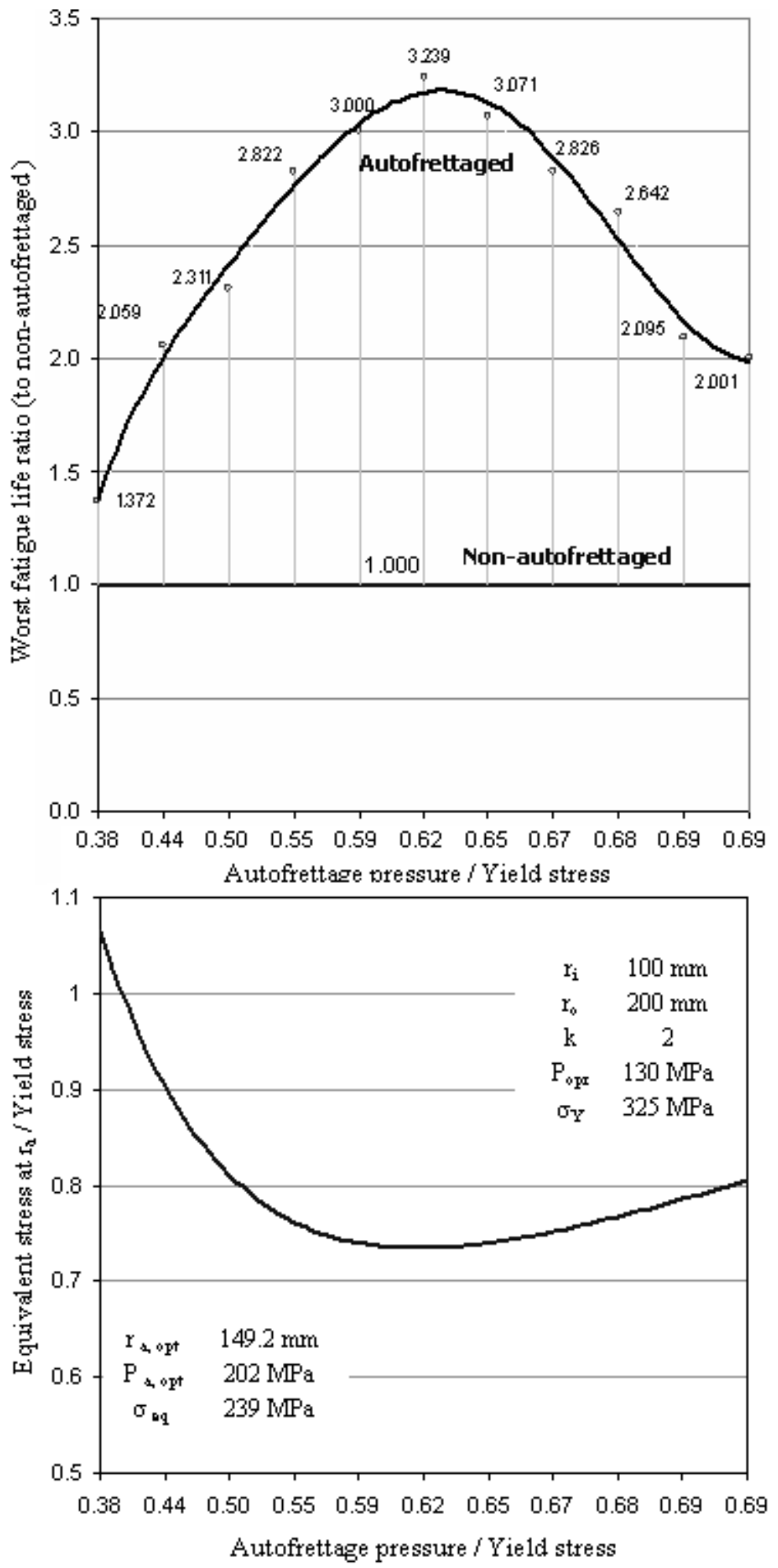

Fig.12. Optimum autofrettage pressure and optimum fatigue life 


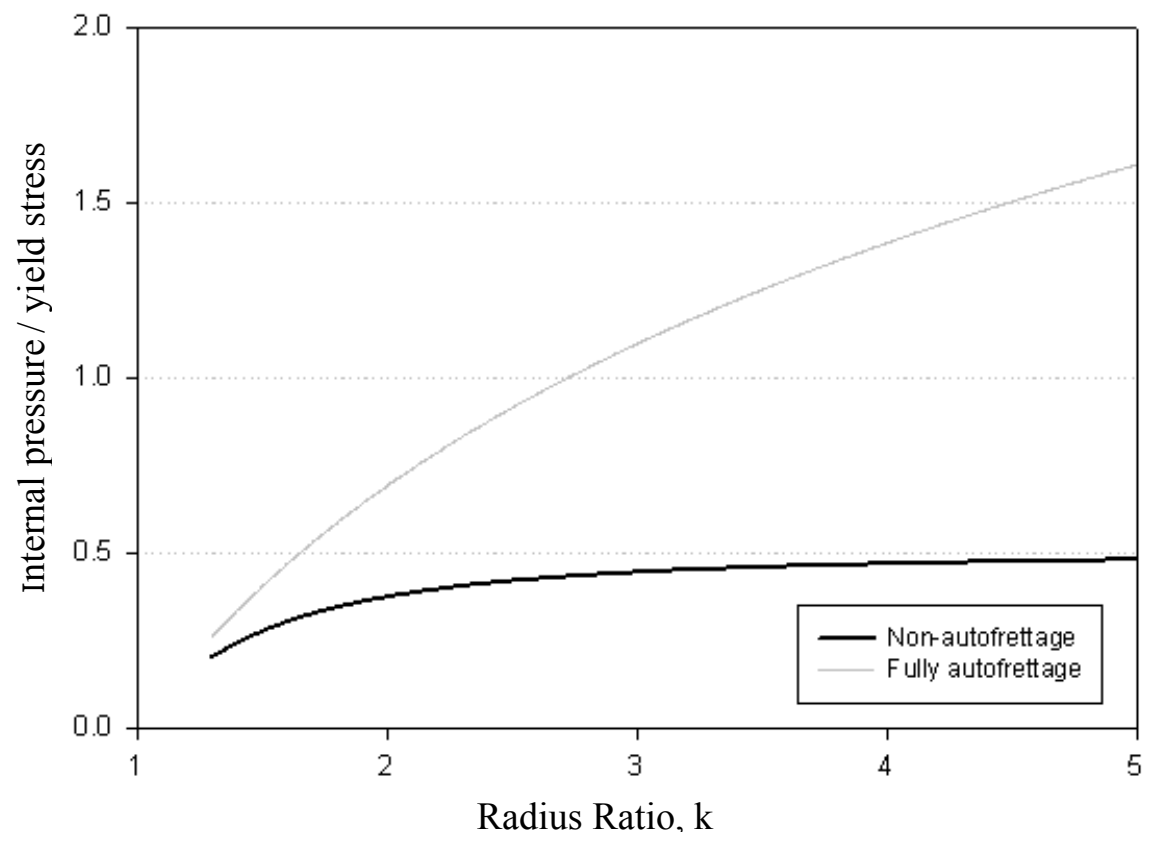

Fig.13. Internal pressure to cause inner surface to yield in fully autofrettaged and non-autofrettaged cylinder, using Tresca criterion.

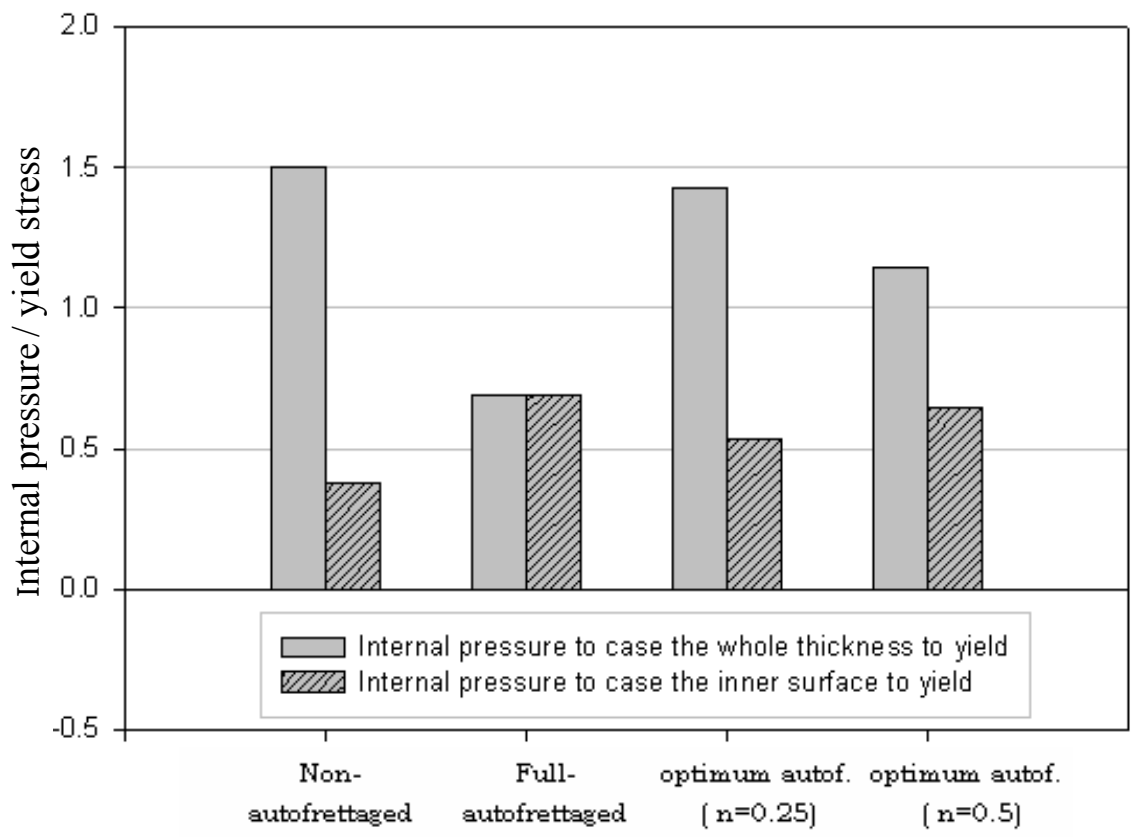

Fig.14. Internal pressure to cause inner and whole thickness to yield 
Table 1. Material properties

\begin{tabular}{|l|l|l|}
\hline Elastic modulus & $\mathrm{E}$ & $203 \mathrm{GPa}$ \\
\hline Yield strength & $\sigma_{\mathrm{Y}}$ & $325 \mathrm{MPa}$ \\
\hline Poisson's ratio & $\mathrm{V}$ & 0.33 \\
\hline Fatigue strength coefficient & $\sigma_{\mathrm{f}}^{\prime}$ & $930 \mathrm{MPa}$ \\
\hline Fatigue strength exponent & $\mathrm{b}$ & -0.095 \\
\hline Fatigue ductility coefficient & $\varepsilon_{\mathrm{f}}^{\prime}$ & 0.26 \\
\hline Fatigue ductility exponent & $\mathrm{C}$ & -0.47 \\
\hline
\end{tabular}

Table 2. Optimum autofrettage pressure and radius, using Tresca and von Mises criteria

\begin{tabular}{|c|c|c|}
\hline & Tresca & von Mises \\
\hline$r_{i}$ & $0.1 \mathrm{~m}$ \\
\hline$r_{0}$ & $0.2 \mathrm{~m}$ \\
\hline$t$ & $0.1 \mathrm{~m}$ \\
\hline$k$ & 2 \\
\hline$P_{\text {opr }}$ & \multicolumn{2}{|c|}{$130 \mathrm{MPa}$} \\
\hline$\sigma_{Y}$ & \multicolumn{2}{|c|}{$325 \mathrm{MPa}$} \\
\hline$n$ & \multicolumn{2}{|c|}{0.4} \\
\hline$m$ & 1.492 & 1.414 \\
\hline$r_{\mathrm{a}, \text { opt }}$ & $149.2 \mathrm{~mm}$ & $141.4 \mathrm{~mm}$ \\
\hline $\mathrm{P}_{\mathrm{a}, \text { opt }}$ & $202 \mathrm{MN} / \mathrm{m}^{2}$ & $194 \mathrm{MN} / \mathrm{m}^{2}$ \\
\hline
\end{tabular}

Table 3. Allowable internal pressure to cause internal surface and whole thickness to yield - cylinder treated with different levels of autofrettage

\begin{tabular}{|c|c|c|}
\hline & $\begin{array}{c}\mathrm{P}_{\mathrm{i}} \text { to cause the internal } \\
\text { surface to yield }\end{array}$ & $\begin{array}{c}\mathrm{P}_{\mathrm{i}} \text { to cause whole } \\
\text { cylinder thickness to } \\
\text { yield }\end{array}$ \\
\hline $\begin{array}{c}\text { No } \\
\text { autofrettage }\end{array}$ & $\frac{\left(k^{2}-1\right)}{2 k^{2}} \sigma_{y}$ & $\frac{\left(k^{2}-1\right)}{2} \sigma_{y}$ \\
\hline $\begin{array}{c}\text { Partial } \\
\text { autofrettage }\end{array}$ & $\frac{\sigma_{y}}{2}\left[2 \ln m+1-\frac{m^{2}}{k^{2}}\right]$ & $\frac{\sigma_{y}}{2}\left[2 / n m+k^{2}-m^{2}\right]$ \\
\hline $\begin{array}{c}\text { Full } \\
\text { autofrettage }\end{array}$ & $\sigma_{y} \ln k$ & $\sigma_{y} \ln k$ \\
\hline
\end{tabular}

